\title{
Wordplay in Shrek Movie and Its Bahasa Indonesian Subtitle
}

\author{
Halimah Tussa'diah ${ }^{1}$ and Iranda Bella Utami ${ }^{2}$ \\ ${ }^{1}$ University of Muhammadiyah Sumatera Utara, Medan, Indonesia, $ه($ (email) halimmaht@umsu.ac.id \\ ${ }^{2}$ University of Muhammadiyah Sumatera Utara, Medan, Indonesia, $ه$ (email) irndbella@gmail.com
}

\begin{abstract}
The objectives of this study were to find out the types of wordplay in Shrek movie and techniques of translating wordplay used in it. Descriptive qualitative method was conducted in this study. The source of the data was obtained by downloading Shrek movie and the script of the Shrek movie. In collecting the data, the researcher watched the movie, wrote the dialogue containing with wordplay, wrote the Bahasa Indonesian subtitle of the English dialogues containing with the wordplay, and classified the types of wordplay according to types of wordplay found in Shrek movie. The data were analyzed by some steps such as; reading, classifying, interpreting and concluding. The findings showed that there were five types of wordplay in Shrek movie, they were Homonymy, Paronymy, Polysemy, Idiom and Morphological development. It was also found three types of technique of translating wordplay, they were Literal translation, Loan translation and Deletion.
\end{abstract}

\section{Keywords:Wordplay, Translation, Shrek movie}

\section{INTRODUCTION}

Watching movie is one of the ways to understand the use of words of wordplay, as it is found in Shrek movie. This movie is actually not a comedy movie, and a comedy movie also must not use words which have funny meaning to deliver it, but it can stimulate the audiences to laugh. It occured because some scenes in the movie after being analyzed, contained with wordplay with a lot of jocularity in it.

As a communicative significance, wordplay in Shrek movie is particular textual settings, it has a communicative effect which can be humorous, attentiongetting, persuasive, or of any other type. Unfortunately not all movies which use foreign language have the same meaning as the source language, like Bahasa Indonesia.To this purpose, a translator who masters both the source language and the target language is needed to convey the message in the movie to the audience. In other words, a translator makes an effort to spread the content of the movie to the audience to understand it by translating it. It is in line with Catford in Malmkjaer (2005 :24) who says that translation is the replacement of textual material in one language (SL) by equivalent textual material in another language (TL). Translation is the linguistic appearance and stylistic shape of a linguistic text that are translated, here he uses the word 'recording' to refer the process of translation.

Dealing with the translation of wordplay in Shrek movie, the most noticeable thing was, the fact that this movie contained with humor as the primary element, although it finally rose a problem, since translating a comedy movie was uneasy. The difficulty in translating humorous movie was reflected in the purpose of the research of this movie. It could be seen from the frequency of this movie which was frequently broadcasted on the national television. It could be said that Shrek movie was very popular in Indonesia. It was interesting for adult audience, although it was actually created to children. It contained with a great deal of verbal humor which children did not understand it, but the adults did very well.

Translation of wordplay in Shrek movie became interesting to the researcher because at least there were two reasons:

Firstly, the researcher decided to study translation because many movie viewers in Indonesia just watched this movie, but they really did not understand the meaning of words that included in types of wordplay. They just enjoyed Bahasa Indonesia subtitle which was the textual versions of the dialogue in a movie of the screen (Spanankaki, 2010: 9), but they did not realize that there were humor elements in it.

Secondly, students could study vocabulary from it, for it contained with abundance of new vocabulary which they did not master yet, and the mastery of vocabulary was compulsory in studying a foreign language as English, especially if the students intended to translate it or if they wanted to know the techniques of translate it. The techniques of translating themselves are very needed since they are very helpful to the viewers to understand better about something, in this study was about the wordplay in Shrek movie. According to Molina and Albir in Dewi Kesuma Nasution (2017, p. 114) that translation techniques are used to describe how the result of translation functions related to the corresponding units in the source text. In this 
case, Molina and Albir used the translation technique as a tool to analyze the result of the translation. Thus, Shrek movie provided interesting material to study.

\section{A. The Objective of the Study}

1. To find out the types of wordplay found in Shrek movie

2. To find out the techniques of translating wordplay in Shrek movie

\section{B. The Significance of the Study}

Theoritically and practically, the result of this study could provide information about wordplay in Shrek movie and techniques of translating wordplay in Shrek movie, besides it could help the students or readers to get some information about wordplay in a comedy movie.and types of techniques of translation.

\section{METHOD}

The study was conducted by using descriptive qualitative design and it was aimed at describing the phenomena found in the translation of wordplay in Shrek movies. This phenomena was related to the types of wordplay ( Phonological Structure, consisted of Homonymy, Homophony and Paronymy. Lexical Development, consisted of Polysemy and Idiom.
Morphological Development and Syntactic Structure ) and the techniques which were used to translate the wordplay ( Literal Translation, Loan, Deletion, Wordplay to Wordplay translation, Rhetorical Device, Situational Translation, Compensation and Editorial Technique ).

The scope of this study was translation and it was limited in wordplay found in Shrek movie. The data were obtained from words and phrases considering wordplay found in Shrek movie and its Bahasa Indonesia subtitle texts in Shrek movie. The data were collected by watching the movie, writing the dialogue based on the movie, writing the Bahasa Indonesia subtitle texts, and classifying the types of wordplay. The technique of analyzing the data was by reading the text, classifying it into types of wordplay and the techniques used to translate it, interpreting the data, and finally concluding based on the findings.

\section{RESULTS AND DISCUSSION}

This part dealt with wordplay in Shrek movie and its Bahasa Indonesia subtitle. The data were the conversation of the characters in Shrek movie with the duration of 120 minutes. The types of wordplay found in Shrek movies were Phonological Structure ( Homonymy and Paronymy ), Lexical Developments ( Polysemy and Idioms ), Morphological Developments and Syntactic Structure, as shown in the below table :

\begin{tabular}{|c|c|c|c|c|c|c|c|}
\hline \multirow{2}{*}{ NO } & \multicolumn{7}{|c|}{ TYPES OF WORDPLAY } \\
\cline { 2 - 6 } & Phonological Structure & Lexical Development & $\begin{array}{l}\text { Morphological } \\
\text { Development }\end{array}$ & $\begin{array}{l}\text { Syntactic } \\
\text { Structure }\end{array}$ \\
\cline { 2 - 8 } & $\mathrm{Hm}$ & $\mathrm{Hp}$ & $\mathrm{Pr}$ & $\mathrm{Pl}$ & $\mathrm{Id}$ & 5 & - \\
\hline 1. & 6 & - & 6 & 4 & 4 & Total : 25 data \\
\hline
\end{tabular}

\begin{tabular}{|c|c|c|c|c|c|c|c|c|}
\hline No & \multicolumn{8}{|c|}{ Technique to Translate Wordplay } \\
\hline & $\mathrm{W}$ & $\mathrm{Rt}$ & $\mathrm{St}$ & $\mathrm{Lt}$ & $\mathrm{Et}$ & $\mathrm{Cm}$ & Ln & Dl \\
\hline 1 & - & - & - & 22 & - & - & 2 & 1 \\
\hline \multicolumn{10}{|c|}{ Total : 25 data } \\
\hline
\end{tabular}

\section{Types of Wordplay}

\section{A. Phonological Structure}

Wordplay based on Phonological Structure could be classified into Homonymy, Homophony and Paronymy. In Shrek movie, there was no single instance of Homophony found.

\section{1) Homonymy}

The basic idea of homonymy is that two words or word groups are identical both in sound and spelling but different in meanings. This condition is often exploited in order to arise humorous effect. In Shrek movie, it was found 6 data of the use of homonymy, for example the word "spell" which means to have magic power but it could also mean another thing.

\section{2) Paronymy}

Paronymy refers to a condition when words or group words are nearly but not quite identical in spelling and pronunciation. There were 6 data of the use Paronymy found in Shrek movie, for example in the word 'eat' and 'beats', both were paronymous since they were nearly but not quite identical in spelling and pronunciation.

\section{B. Lexical Developments}

\section{1) Polysemy}

The difference between Polysemy and homonymy is subtle since both are words with the same spelling and pronunciation but different meaning. In this study, the difference between both could be seen from their meaning. Words with the same spelling and pronunciation but different meaning is related to Polysemy. It was found 4 data of the use of Polysemy in this movie.

\section{2) Idioms}

Idioms can be defined as a group of words whose meaning is different from individual words. The instance of wordplay in which idioms could be interpreted literally and 
figuratively was often found in Shrek movie. The misunderstanding between the speaker and the hearer was effective to create humorous effect for the audience. There were 4 data of Idiom used in this movie, for instance "I have to save my ass".

\section{Morphological Development}

Wordplay can be formed through morphogical mechanism, such as derivation and compounding. The simple definition of derivation is formation of lexemes. The formation can be done by means of affixation, concersion, reduplication, etc.It was found 5 data based on affixation and formation of a word by means of an affix in the dialogue of this movie, for example the word "hard" to be "hardly".

\section{Syntactic Structure}

There was no division in Syntactic Structure as Phonological Structure is, and in Shrek movie, there was no single instance of Syntactic Structure found.

\section{Technique to Translate the Wordplay in Shrek movie}

There were 3 techniques found in the translation of wordplay in Shrek movie. They were Literal translation, Loan translation, and Deletion out of 8 techniques of translation ( the techniques applied were according to Humanika, $2012: 3$ ).

\section{1) Literal Translation}

In Literal translation, the translator translates the wordplay word-for-word. As a result, the wordplay was sometimes lost in the target text, for example the phrase 'ogre-to-man. It was actually a play on the idiom man-toman. However, because Shrek was an ogre and Prince Charming was a man, Shrek replaced the word 'man' with 'ogre'. By the translator, the idiom was translated literally. As the result, the idiomatic meaning and the wordplay were lost in the target text at the same time. This kind of technique was applied 22 data in Shrek movie.

\section{2) Loan Translation}

Loan translation refers to the technique in which the translator directly transfers the Source Translation wordplay to the Target Translation without any change. The wordplay was translated the way it was, like the proper names in Shre kmovie. There were 2 data applied this technique.

\section{3) Deletion}

Deletion means that the translator simply omits the part where the wordplay takes place. Sometimes the wordplay was omitted for cultural reason. The wordplay was omitted because it was probably seen as profanity which was considered inappropriate for Indonesian audience, and was only used once in this movie.

\section{CONCLUSIONS}

Based on the findings and discussions, there were some points that could be concluded from this study:

a. There were 5 types of wordplay identified in Shrek movie. They were in Phonological Structure ( Homonymy and Paronymy ), Lexical Development (
Polysemy and Idioms ) and Morphological development. Out of the total 25 data, Homonymy was with 6 data. While lexical developments : polysemy and idioms were in the lowest rank with 4 data. The other types of wordplay had not found in this Shrek script movie.

b. The techniques used by the translator to translate the wordplay in Shrek movie into Bahasa Indonesia were literal translation, loan translation and deletion. Literal translation was the most frequently used with 22 data, Loan translation with 2 data and Deletion with 1data.

\section{REFERENCES}

[1] Humanika, E.S. (2011). "Ideologi Penerjemahan Wordplay dalam Alice's Adventure in Wonderland ke dalam Bahasa Indonesia". DOI: 10.26499/wdprw.v39i2.34.

[2] Malmkjaer, K. (2005). Linguistics and the Language of Translation. Edinburg: Edinburg University Press Ltd.

[3] Nasution, D.K. (2017). “Translating Malay Incantation Texts of Sea Offerings Into English: An Analysis of Translation Techniques and Translation Accuracy". International Journal of English Language \& Translation Studies, 05, 2308-5460.

[4] Spanakaki, K. (2007). "Translating Humor for Subtitling", http://www.bokorlang.com/journal/40humor.htm Retrieved on 18 Februari 2014.

[5] .http://www.stanford.edu/ eckert/PDF/jakobson.p df. Retrieved on 18Februari 2014.

[6] http://www2.hawaii.edu/ bergen ling640G/lec/lec4.htm. Retrieved on 9 April 2014. 